\title{
A Validated High-Performance Thin-Layer Chromatography (Hptlc) Method for the Quantitative Determination of Tricin in Two Spergularia Species
}

\author{
Omnia Gamal El-Dien, Eman Shawky", Amal H. Aly, Rokia M. Abdallah, Nabil A. Abdel-Salam \\ Pharmacognosy Department, Faculty of Pharmacy, University of Alexandria, Alexandria, Egypt \\ Email: "shawkyeman@yahoo.com
}

Received September 24, 2013; revised October 26, 2013; accepted November 8, 2013

Copyright (C) 2013 Omnia Gamal El-Dien et al. This is an open access article distributed under the Creative Commons Attribution License, which permits unrestricted use, distribution, and reproduction in any medium, provided the original work is properly cited.

\begin{abstract}
A simple, sensitive, precise and robust high-performance thin-layer chromatographic (HPTLC) method for analysis of tricin has been developed and validated for the determination of tricin in genus Spergularia. Analysis of tricin was performed on pre-coated TLC aluminum plates with silica gel as the stationary phase. Linear ascending development was carried out in double twin trough glass chamber saturated with a mobile phase consisting of chloroform: methanol (37:3 $\mathrm{v} / \mathrm{v})$. Spectro-densitometric scanning was performed by TLC scanner III (CAMAG) in absorbance mode at the wavelength of $270 \mathrm{~nm}$. The system was found to give compact spots for tricin ( $\mathrm{Rf}$ value of $0.34 \pm 0.04$ ). The linear regression analysis data for the calibration plots showed a good linear relationship with $\mathrm{r}^{2}=0.9981$ in the concentration range $2-15 \mu \mathrm{l}$ with respect to peak area. According to the International Conference on Harmonization (ICH) guidelines, the method was validated for precision, recovery, and robustness. The tricin content quantified from Spergularia marina and $S$. daiandra was found to be $0.398 \mathrm{mg} / 100 \mathrm{~g}$ and $1.642 \mathrm{mg} / 100 \mathrm{~g}$ fresh weight, respectively. Statistical analysis of the data showed that the method is reproducible and selective for the estimation of tricin.
\end{abstract}

Keywords: Spergularia marina; Spergularia diandra; HPTLC; Quantitative; Tricin

\section{Introduction}

Tricin possesses several biological properties that are superior to other flavonoids and polyphenols in terms of agricultural, nutraceutical and pharmaceutical values [1]. It has long been credited for its beneficial effects: as an antioxidant due to its potent inhibition of lipoperoxidation and its sparing effect on vitamin $\mathrm{E}$ in erythrocyte membranes; as an antiviral; antihistaminic; immunemodu-latory and anti-tubercular activities [2-4]. The promising anti-ulcerogenic activity of tricin and its 7-glucoside was recently reported with a curative ratio of 77 and $79 \%$, respectively [5]. Tricin is a potent COX (Cyclooxygenase) inhibitor. The inhibition of COX enzyme activity by tricin was apparently isoenzyme-nonselective, which renders it more comparable with non-steroidal anti-inflammatory drugs, such as sulindac and aspirin, rather than to coxibs [6-8].

One of the most prominent and well documented features of tricin is its potential antitumor/anticancer activity.

${ }^{*}$ Corresponding author.
Based on a study of structure-activity relationships of flavonoid-induced cytotoxicity on human leukemia cells, tricin is considered one of the most potent anti-cancer agents tested so far and this is most probably due to the stability of its structure [9].

Recently a simple HPLC method for the quantitation of tricin in human plasma has been reported and crossvalidated in mouse plasma, liver and small intestinal mucosa. The work was designed to contribute to the development of tricin as a potential chemo-preventive agent in humans [10].

Being the dominant flavone pigment in whole wheat meal, tricin has prompted the elaboration of a method for tricin isolation and quantification, based on ultrasonicassisted extraction and ultra-performance HPLC purification, and guided by electrospray ionization MS [11].

A recent HPLC method for tricin isolation and quantification in the pressed juice of Medicago sativa was established [1]. In addition, a simple, precise, and rapid method was developed for the determination of tricin and 4'-methoxy-tricin in the Tibetan herbal medicine of $P y-$ 
rethrum tatsienense by the high-performance liquid chroma-tographic technique coupled with photodiode array detection [12].

Among the modern Analytical tools, HPTLC is a powerful analytical method equally suitable for qualitative and quantitative analytical tasks. HPTLC is playing an important role in today's analytical world, not in competition to HPLC but as a complementary method [13].

HPTLC produces visible chromatograms complex information about the entire sample available at a glance. Multiple samples are seen simultaneously, so that reference and test samples can be compared for identification. Similarities and differences are immediately apparent and with the help of the image comparison. Several chromatograms can be compared directly, even from different plates. They can be evaluated either by the image based software video-scan or by scanning densitometry with TLC scanner, measuring the absorption and/or fluorescence of the substances on the plate. TLC is an offline technique: the subsequent steps are relatively independent, allowing parallel treatment of multiple samples during chromatography, derivatization and detection.

We managed to isolate tricin for the first time from genus Spergularia. Tricin was isolated from the chloroform fraction of Spergularia marina; meanwhile it was found in the chloroformic fraction of Spergularia diandra in a large amount.

In view of the fore-mentioned points, the aim of this work is to develop a simple, non expensive, accurate, specific and repeatable HPTLC method for the determination of tricin in Genus Spergularia. Literature review revealed that only one HPLTC method has been reported for the analysis of tricin among other five flavonoids, but the method was not thoroughly validated [14].

\section{Experimental}

\subsection{Chemicals and Reagents}

HPTLC analyses were performed on Merck $20 \mathrm{~cm} \times 10$ $\mathrm{cm}(0.25 \mathrm{~mm})$ plates. Tricin used as standard material was obtained from the Department of Pharmacognosy, Faculty of Pharmacy, University of Alexandria and tested for its purity by TLC and spectroscopic method. All the reagents used in the experiment were of analytical grade and were supplied by Merck, Darmstadt, Germany.

\subsection{Preparation of Standard Solution}

A weight of $4.0 \mathrm{mg}$ of standard tricin was accurately weighed, quantitatively transferred into a $10 \mathrm{ml}$ volumetric flask, dissolved in methanol and the volume was adjusted with the same solvent.

\subsection{Preparation of Sample Solutions}

Fresh aerial parts, $500 \mathrm{~g}$ of each of Spergularia marina and Spergularia diandra were accurately weighed and exhaustively extracted using (2 L) 70\% ethanol at room temperature. Each alcoholic extract was concentrated to $200 \mathrm{ml}$ volume, fractionated successively by $(600 \mathrm{ml})$ petroleum ether, then by $(600 \mathrm{ml})$ chlorofrorm. The chloroform fraction was evaporated under reduced pressure to give $440 \mathrm{mg}$ of extract for S. marina and $770 \mathrm{mg}$ for S. diandra. A weight of $225 \mathrm{mg}$ of each of the chloroformic fraction of Spergularia marina and Spergularia diandra were accurately weighed, dissolved in a mixture of methanol and chloroform (8:2), transferred quantitatively to $10 \mathrm{ml}$ volumetric flask, adjusted to volume with the same mixture and shaken to mix thoroughly to give samples A and B, respectively.

\subsection{HPTLC-Densitometric Procedure}

\subsubsection{Instrumentation}

Sample solutions for HPTLC analyses were applied by means of a CAMAG (Wilmington, NC) Linomat IV automated spray-on band applicator. Zones were quantified by linear scanning at $270 \mathrm{~nm}$ with a CAMAG TLC Scanner 3 with a deuterium source in the reflection mode, slit dimension settings of length 6 and width 0.1 , monochromator bandwidth $20 \mathrm{~nm}$, and a scanning rate of 15 $\mathrm{mm} \cdot \mathrm{s}^{-1}$. The peak areas of chromatograms were determined using CATSTLC software (version 4.X).

\subsubsection{Chromatographic Procedure}

Sample and standard solutions were applied in the form of bands on pre-coated HPTLC silica gel plates $60 \mathrm{~F}-254$ $(20 \mathrm{~cm} \times 10 \mathrm{~cm}$ with $250 \mu \mathrm{m}$ thickness) by means of Linomat IV automated spray-on band applicator operated with the following settings: band length $6 \mathrm{~mm}$, application rate $15 \mathrm{~s} / \mu 1$, distance between each two bands $4 \mathrm{~mm}$, distance from the plate side edge $1 \mathrm{~cm}$, distance from the bottom of the plate $1 \mathrm{~cm}$.

The volumes applied for routine analysis were duplicate $1.0 \mu \mathrm{l}, 3.0 \mu \mathrm{l}$ and $5.0 \mu \mathrm{l}$ of the TLC tricin standard $(0.4,1.2$ and $2.0 \mu \mathrm{g})$ and triplicate $6 \mu \mathrm{l}$ and $4 \mu \mathrm{l}$ aliquots of samples solutions A and B respectively. A volume of $20 \mathrm{ml}$ of mobile phase (system IV) were used for development.

Linear ascending development of the plates was carried out in $20 \mathrm{~cm} \times 20 \mathrm{~cm}$ Camag HPTLC twin trough chamber saturated with the mobile phase. The optimized chamber saturation time for the mobile phase was $30 \mathrm{~min}$ at room temperature. Plates were developed to a distance of $8 \mathrm{~cm}$ beyond the origin. The development time was 17 min. After development, the plates were air-dried for 5 min. Densitometric scanning was performed on Camag TLC scanner III in the reflectance-absorbance mode at $\lambda$ $270 \mathrm{~nm}$ and operated by WINCATS software (V. 3.1). The source of radiation utilized was deuterium lamp 
emitting a continuous UV spectrum between 190 and 400 $\mathrm{nm}$. The slit dimension was kept at $6 \mathrm{~mm} \times 0.1 \mathrm{~mm}$. Concentrations of the samples and standards chromatographed were determined from the intensity of diffusely reflected light. Evaluation was done by peak area measurement with linear regression.

\subsection{Validation}

The method was validated according to the ICH guidelines on the validation of analytical methods [15]. All results were expressed as percentages, where n represents the number of values. For the statistical analysis, Excel 2003 (Microsoft Office) was used. A 5\% level of significance was selected.

\subsubsection{Calibration and Quantification}

As recommended by the International Committee on Harmonization ( $\mathrm{ICH}$ ) guidelines [15], a calibration curve was established using six analyte concentrations (1.0, 2.0, 3.0, 4.0, 5.0 and $6.0 \mu \mathrm{l} /$ zone) of the TLC standard applied in triplicate, representing $0.4-2.4 \mu \mathrm{g}$ of tricin. For routine analytical procedures, a three-point calibration curve within this range was used, produced by applying duplicate $1.0,3.0$ and $5.0 \mu \mathrm{l}(0.4,1.2,2.0 \mu \mathrm{g})$ of the HPTLC standard on each plate.

\subsubsection{Specificity}

The specificity of the method was determined by analyzing standard drug and test samples. The spots for tricin and samples were confirmed by comparing the $\mathrm{Rf}$ and spectrum of the spot with that of a standard. The peak purity of tricin was assessed by comparing the spectra at three different levels, that is, peak start (S), peak middle $(\mathrm{M})$, and peak end (E) positions of the spot.

\subsubsection{Accuracy}

The accuracy of the method was validated by a standard addition analysis. The sample solutions were spiked with three different known concentrations of tricin. An aliquot of $2 \mathrm{ml}$ of sample B solution of known previously determined concentration $(0.24 \mathrm{mg} / \mathrm{ml})$ was mixed with $3 \mathrm{ml}$ of standard tricin solution $(0.12 \mathrm{mg} / \mathrm{ml})$ to give mixture 1 , another $2 \mathrm{ml}$ aliquot of the same sample solution was mixed with $3 \mathrm{ml}$ of standard tricin solution $(0.24 \mathrm{mg} / \mathrm{ml})$ to give mixture 2, and a third $2 \mathrm{ml}$ aliquot of the same sample solution was mixed with $3 \mathrm{ml}$ of standard tricin solution $(0.36 \mathrm{mg} / \mathrm{ml})$ to give mixture 3 . The original and the three fortified sample solutions (mixtures 1, 2 and 3) were analyzed on the same plate by application of triplicate $4.0 \mu \mathrm{l}, 6.0 \mu \mathrm{l}, 4.0 \mu \mathrm{l}$ and $4.0 \mu \mathrm{l}$ volumes, respectively, in addition to the three standards described earlier for routine analyses which were applied in duplicate. The difference between the expected concentrations and the found ones was calculated to determine the accuracy of the method.

\subsubsection{Precision}

In accordance with the ICH guidelines [15], precision was determined by independent repeated analysis of six different tricin standard solutions by the use of the same equipment and the same analytical procedure in the same laboratory and on the same plate. The assay was repeated in the same day for intra-day precision and on different days to obtain inter-day precision.

\subsubsection{Limit of Detection (LOD) and Limit of Quantification (LOQ)}

According to the ICH guidelines, the detection limit (DL) may be expressed as $\mathrm{DL}=3.3 \mathrm{\sigma} / \mathrm{S}$, while, the quantitation limit $(\mathrm{QL})$ may be expressed as $\mathrm{QL}=10 \sigma / \mathrm{S}$, where $\sigma=$ the standard deviation of the response $S=$ the slope of the calibration curve. The slope $\mathrm{S}$ is estimated from the calibration curve. The estimate of $\sigma$ was carried out by studying the calibration curves, where the standard deviations of $y$-intercepts of regression lines were used as the standard deviation.

\section{Results and Discussion}

Mixtures of several mobile phases were tried to separate spot of tricin from other spots and get stable peak. The solvent system used was System chloroform: methanol $(37: 3 \mathrm{v} / \mathrm{v})$ was selected for analysis of tricin, which gave good resolution. Good chromatogram in Figures 1-3 was attained with $\mathrm{Rf}$ value $0.38 \pm 0.04$. The wavelength of 270 $\mathrm{nm}$ was used for quantification of sample as it gave the best sensitivity.

The selectivity of the separation and the specificity of the detection were shown by the densitograms and comparison of the superimposed UV spectra, respectively (Figure 4). The peak purity of tricin was assessed by

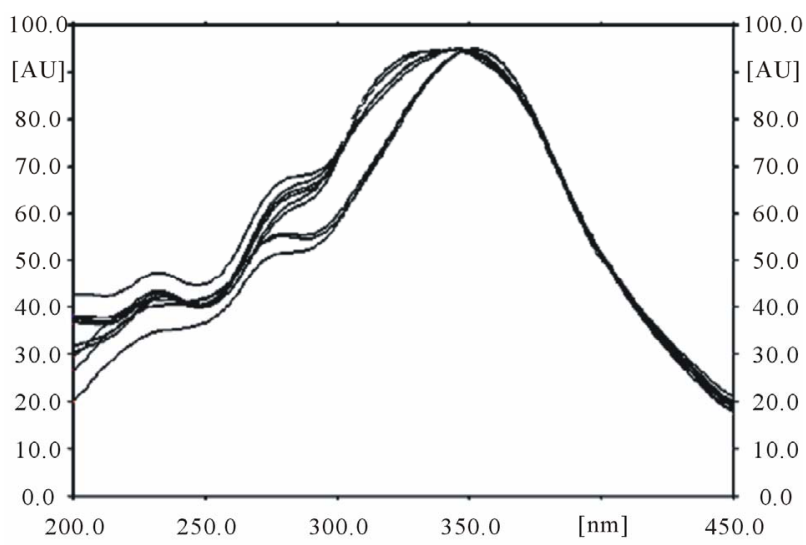

Figure 1. Overlay of in-situ absorption spectra obtained from the band of standard tricin and the corresponding band obtained from chloroform extracts of $S$. marina and $S$. diandra scanning from 200 to $400 \mathrm{~nm}$. 




Figure 2. HPTLC scan-densitogram showing the separation of tricin (7) from other components in the sample $A$ at 270 nm.



Figure 3. HPTLC scan-densitogram showing the separation of tricin (3) from other components in the sample B at 270 nm.

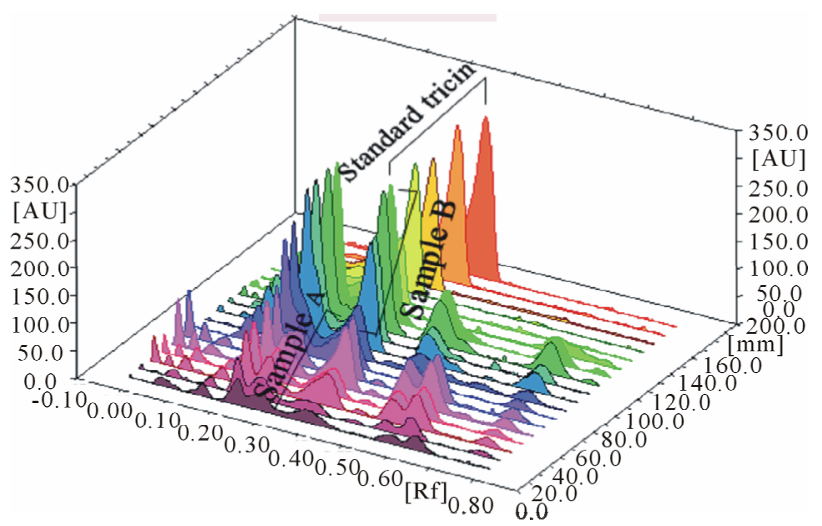

Figure 4. A 3-dimential of a series of sample A, B and standard tricin applied on the same plate with increasing concentrations showing an increase in the area of successive peaks in samples and standard.

comparing its respective spectra at the peak start, apex, and peak end.

Visual observation of the calibration curves was done which reveals that the calibration curve is linear. The intercept of the calibration lines is slightly different from zero. From these we can say that, this kind of methods shows saturation on the spots and because of that it produces curved calibrations. However, here linearity can fit the calibration responses at narrow range but intercept deviate from zero. The results showed linear relationship between the peak areas and the tricin concentrations. The plot was linear in the range of $0.4-2.4 \mu \mathrm{g} / \mathrm{spot}(\mathbf{y}=7463$ $\left.\mathrm{x}+583.6, \mathrm{r}^{2}=0.998\right)$. The three-point calibration was repeated many times and was also found to have a linear regression correlation coefficient of 0.999 .

LOD and LOQ were found to be 0.0513 and 0.155 $\mu \mathrm{g} /$ spot respectively. Results are shown in Table 1 .

The results of repeatability and intermediate precision study of tricin are depicted in Table 2. The developed method was found to be precise as the \%RSD values for repeatability and intermediate precision studies were less than $2 \%$.

Results of recovery studies by addition of tricin standard in triplicate are depicted in Table 3.

The method was found to be robust by studying the effect of alteration of mobile phase composition. The results of change in mobile phase composition in terms of standard deviation of the peak areas calculated as the \% RSD was found to be less than $2 \%$ (Table 4).

The method was employed for the determination of tricin content in the total extract of Spergularia marina and $S$. diandra, where $\% \mathrm{w} / \mathrm{w}$ tricin in fresh total weight was found to be $0.398 \mathrm{mg} / 100 \mathrm{~g}$ fresh weight and 1.642 $\mathrm{mg} / 100 \mathrm{~g}$ fresh weight for Spergularia marina and $S$. diandra, respectively.

\section{Conclusion}

TLC and TLC-densitometry have been largely investigated for purity testing, pharmaceutical dosage form assay and herbal fingerprinting [16]. These methods are flexible and cost-effective and present the advantage of the simultaneous processing of standards and samples with versatile detection possibilities, including a great variety of post-chromatographic derivatization reagents due to the short analysis time and low solvent consumption. The results of the analysis of marketed formulation using the proposed HPTLC method are highly reproducible and reliable. HPTLC method is found to be simple, sensitive, accurate, precise, specific, robust and economi-

Table 1. Linear regression data for the calibration curve of tricin.

\begin{tabular}{cc}
\hline & Tricin \\
\hline Linearity range $(\boldsymbol{\mu g} / \mathbf{s p o t})$ & $0.32-2.88$ \\
Intercept (a) & 583.6 \\
Slope $(\mathbf{b})$ & 7463 \\
Correlation coefficient $(\mathbf{r})$ & 0.999172 \\
$\mathbf{L O D}(\boldsymbol{\mu g} / \mathbf{s p o t})$ & 0.051238 \\
$\mathbf{L O Q}(\boldsymbol{\mu g} / \mathbf{s p o t})$ & 0.155266 \\
\hline
\end{tabular}


Table 2. Precision of the HPTLC method for the determination of tricin (repeatability).

\begin{tabular}{|c|c|c|c|c|c|c|}
\hline \multirow{2}{*}{ Experiment number } & \multicolumn{3}{|c|}{ Intra-day precision } & \multicolumn{3}{|c|}{ Inter-day precision } \\
\hline & Concentration $(\mu \mathrm{g} / \mathrm{spot})$ & Mean \pm SD & RSD \% & Concentration $(\mu \mathrm{g} / \mathrm{spot})$ & Mean \pm SD & RSD \% \\
\hline 1 & $\begin{array}{l}0.399 \\
0.406 \\
0.398\end{array}$ & $\begin{array}{c}0.401 \\
\pm \\
0.004\end{array}$ & 1.108 & $\begin{array}{l}0.401 \\
0.402 \\
0.409\end{array}$ & $\begin{array}{c}0.404 \\
\pm \\
0.004\end{array}$ & 1.046 \\
\hline 2 & $\begin{array}{l}0.808 \\
0.823 \\
0.797\end{array}$ & $\begin{array}{c}0.809 \\
\pm \\
0.013\end{array}$ & 1.624 & $\begin{array}{l}0.809 \\
0.805 \\
0.807\end{array}$ & $\begin{array}{c}0.807 \\
\pm \\
0.002\end{array}$ & 0.253 \\
\hline 3 & $\begin{array}{l}1.218 \\
1.216 \\
1.221\end{array}$ & $\begin{array}{c}1.218 \\
\pm \\
0.003\end{array}$ & 0.207 & $\begin{array}{l}1.218 \\
1.211 \\
1.195\end{array}$ & $\begin{array}{c}1.208 \\
\pm \\
0.012\end{array}$ & 0.969 \\
\hline 4 & $\begin{array}{l}1.583 \\
1.622 \\
1.640\end{array}$ & $\begin{array}{c}1.615 \\
\pm \\
0.029\end{array}$ & 1.815 & $\begin{array}{l}1.615 \\
1.615 \\
1.630\end{array}$ & $\begin{array}{c}1.620 \\
\pm \\
0.009\end{array}$ & 0.546 \\
\hline 5 & $\begin{array}{l}1.984 \\
2.002 \\
2.038\end{array}$ & $\begin{array}{c}2.008 \\
\pm \\
0.028\end{array}$ & 1.369 & $\begin{array}{l}2.008 \\
2.027 \\
2.009\end{array}$ & $\begin{array}{c}2.015 \\
\pm \\
0.010\end{array}$ & 0.504 \\
\hline 6 & $\begin{array}{l}2.273 \\
2.269 \\
2.348\end{array}$ & $\begin{array}{c}2.297 \\
\pm \\
0.045\end{array}$ & 1.941 & $\begin{array}{l}2.422 \\
2.362 \\
2.348\end{array}$ & $\begin{array}{c}2.377 \\
\pm \\
0.040\end{array}$ & 1.662 \\
\hline
\end{tabular}

Table 3. Results of the standard addition experiments.

\begin{tabular}{|c|c|c|c|c|c|}
\hline Mix. & $\begin{array}{l}\text { Concentration of tricin } \\
\text { in sample }(\mathrm{mg} / \mathrm{ml})\end{array}$ & $\begin{array}{c}\text { Concentration of } \\
\text { tricin added }(\mathrm{mg} / \mathrm{ml})\end{array}$ & $\begin{array}{l}\text { Concentration of tricin found } \\
\text { in mixture }(\mathrm{mg} / \mathrm{ml})^{*}\end{array}$ & Recovery $(\%) \pm \mathrm{SD}$ & RSD \% \\
\hline 1 & 0.24 & 0.12 & 0.166 & $98.95 \pm 1.56$ & 1.59 \\
\hline 2 & 0.24 & 0.24 & 0.242 & $100.66 \pm 1.614$ & 1.6 \\
\hline 3 & 0.24 & 0.36 & 0.317 & $101.48 \pm 1.44$ & 1.41 \\
\hline
\end{tabular}

*Each concentration is the average of three determinations.

Table 4. Robustness testing.

\begin{tabular}{ccc}
\hline Parameter & S.D. & R.S.D. \% \\
\hline Mobile phase composition & 0.072 & 1.3 \\
Amount of mobile phase & 0.03 & 0.82 \\
Time from spotting to chromatography & 0.05 & 0.97 \\
Time from chromatography to scanning & 0.06 & 0.74 \\
\hline
\end{tabular}

cal and it can be used for the routine analysis of tricin in genus Spergularia L.

\section{REFERENCES}

[1] J.-M. Zhou and R. K. Ibrahim, "Tricin-A Potential Multifunctional Nutraceutical," Phytochemistry Reviews, Vol. 9, No. 3, 2010, pp. 413-424. http://dx.doi.org/10.1007/s11101-009-9161-5

[2] M. Watanabe, "Antioxidative Phenolic Compounds from Japanese Barnyard Millet Echinochlo autilis) Grains," Journal of Agricultural and Food Chemistry, Vol. 47, No. 11, 1999, pp. 4500-4505. http://dx.doi.org/10.1021/jf990498s

[3] Y. S. Kwon, E. Y. Kim, W. J. Kim, et al., "Antioxidant Constituents from Setariaviridis," Archives of Pharmacal Research, Vol. 25, No. 3, 2002, pp. 300-305. http://dx.doi.org/10.1007/BF02976630

[4] Y. S. Kwon and C. M. Kim, "Antioxidant Constituents from the Stem of Sorghum Bicolor," Archives of Pharmacal Research, Vol. 26, No. 7, 2003, pp. 535-539. http://dx.doi.org/10.1007/BF02976877

[5] A. S. Awaad, N. H. Mohamed, D. J. Maitland, et al., "Antiulcerogenic Activity of Extract and Some Isolated Flavonoids from Desmostachia bipinnata L. Stapf," Records of Natural Products, Vol. 2, No. 3, 2008, pp. 76-82.

[6] H. Cai, M. Al-Fayez, R. G. Tunstall, et al., "The Rice Bran Constituenttricin Potently Inhibits Cyclooxygenase Enzymes and Interferes with Intestinal Carcinogenesis in Apc Minmice," Molecular Cancer Therapeutics, Vol. 4, No. 9, 2005, pp. 1287-1292. http://dx.doi.org/10.1158/1535-7163.MCT-05-0165

[7] H. Cai, S. Sale, R. Schmid, et al., "Flavones as Colorectal Cancer Chemopreventive Agents: Phenol-O-Methylation Enhances Efficacy," Cancer Prevention Research, Vol. 2, No. 8, 2009, pp. 743-750. http://dx.doi.org/10.1158/1940-6207.CAPR-09-0081

[8] J. Yan, L. Sun, X. Zhang, et al., "A New Flavone from Lycopodium Japonicum,” Heterocycles, Vol. 65, No. 3, 2005, pp. 661-666.

http://dx.doi.org/10.3987/COM-04-10314

[9] K. Plochmann, G. Korte, E. Koutsilieri, et al., "Structure-Activity Relationships of Flavonoid-Induced Cytotoxicity on Human Leukemia Cells," Archives of Biochemistry and Biophysics, Vol. 460, 2007, pp. 1-9. http://dx.doi.org/10.1016/j.abb.2007.02.003 
[10] H. Cai, W. P. Steward and A. J. Gescher, "Determination of the Putative Cancer Chemopreventive Flavone Tricin in Plasma and Tissues of Mice by HPLC with UV-Visible Detection," Biomedical Chromatography, Vol. 19, No. 7, 2005, pp. 518-533. http://dx.doi.org/10.1002/bmc.473

[11] S. Zhao, L.-J. Zhao, X.-H. Gu, X.-Z. Wang and J. C. Tian, "Determination of Tricin in Wheat Grain by Ultra Performance Liquid Chromatography Tandem Mass Spectrometry," Chinese Journal of Analytical Chemistry, Vol. 37, No. 6, 2009, pp. 873-876.

[12] X. Liu, A.-M. Yang and Y.-P. Shi, "Determination of Flavonoids in Tibetan Herbal Medicine of Pyrethrum tatsienense by HPLC with Photodiode Array Detection," Journal of Analytical Chemistry, Vol. 63, No. 5, 2008, pp. 472-476. http://dx.doi.org/10.1134/S1061934808050122

[13] "High Performance Thin Layer Chromatography (HPTLC):
A Modern Analytical Tool for Biological Analysis," Nature and Science, Vol. 8, No. 10, 2010, pp. 58-61.

[14] "HPTLC Analysis of the Flavonoids in Eight Species of Indocalamus Leaves," Journal of Planar Chromatography, Vol. 24, No. 5, 2011, pp. 394-399.

[15] ICH-Guidelines Q2(R1), Validation of Analytical Procedures: Text and Methodology.

http://www.ich.org/fileadmin/Public_Web_Site/ICH_Pro ducts/Guidelines/Quality/Q2_R1/Step4/Q2_R1_Guideli ne.pdf

[16] H. Hajimehdipoor, M. Khanavi, H. Zahedi, Z. Abedi, N. Kalantari Khandani, N. Adib and M. Pirali Hamedani, "Fingerprint Study of Thymus spp. by TLC," Journal of Medicinal Plants, Vol. 8, No. 31, 2009, pp. 19-24. 